\title{
Biophotonics in veterinary medicine: the first steps toward clinical translation
}

Blaž Cugmas, Jānis Spīgulis

Blaž Cugmas, Jānis Spīgulis, "Biophotonics in veterinary medicine: the first steps toward clinical translation

," Proc. SPIE 10885, Optical Diagnostics and Sensing XIX: Toward Point-ofCare Diagnostics, 108850I (20 February 2019); doi: 10.1117/12.2507980

SPIE. Event: SPIE BiOS, 2019, San Francisco, California, United States 


\title{
Biophotonics in veterinary medicine: the first steps toward clinical translation
}

\author{
Blaž Cugmas*, Jānis Spīgulis \\ Biophotonics Laboratory, Institute of Atomic Physics and Spectroscopy, University of Latvia, \\ Raina Blvd. 19, LV-1586, Riga, Latvia
}

\begin{abstract}
In this paper, we analyzed the current situation and the potential of biophotonics and biomedical optics in veterinary medicine. Promising optical techniques such as optical coherence tomography, pulse oximeter, and hyperspectral imaging have been clinically translated into human medicine. But even though human and small animal medicine share personalized and state-of-the-art approach, biophotonics remains rarely exploited in the canine and feline medicine. However, there are some biophotonics studies in veterinary oncology which addressed tumor diagnosis (skin and subcutaneous tumors), prognosis (lymphoma), and therapy (clear surgical margins). Visible and near-infrared spectroscopy served for measuring various physiological parameters related to circulation, and photobiomodulation therapy was often used for the management of wounds, skin conditions, and orthopedic problems. In the research, the most popular clinically translated technique is thermography which was applied for the diagnosis of orthopedic problems and diseases as infections and hyperthyroidism. The future optical devices for small animals such as dogs and cats should be robust and resilient to damage (e.g., due to biting, chewing), offering user-friendly and short measurements. In veterinary oncology, biophotonics could replace invasive fine-needle aspiration procedure. The potential of a pulse oximeter for pet monitoring has yet to be explored. What is more, photobiomodulation efficiency should be tested in an extensive clinical (in vivo) study. The technique would be very beneficial in dentistry which currently requires expensive and risky anesthesia.
\end{abstract}

Keywords: biophotonics, biomedical optics, veterinary medicine, clinical translational, small animals, pulse oximeter, optical coherence tomography, dogs

\section{INTRODUCTION}

Recently, we have seen a great advance in biophotonics and biomedical optics ${ }^{1}$. The promising technologies as optical coherence tomography (OCT), diffuse optical spectroscopy and imaging (also hyperspectral imaging, HSI), fluorescence imaging, and photoacoustic microscopy have been translated to the clinics in order to improve human health and wellbeing $^{2}$. Especially, oncology, dermatology, surgery, urology, and dentistry benefited substantially.

Even though many technologies (including MRI and CT) were introduced to small animal veterinary medicine, biophotonics remains rarely exploited. It is obvious that most techniques are primarily developed for humans. Therefore, only if a specific technique can be directly or with minor adjustments applied to animals, it gets translated into veterinary medicine (Figure 1). Since animal health and well-being needs differ from those of human's, a clinical translation should be realized directly.

In this paper, we briefly describe the field of veterinary medicine compared to human medicine. We continue with the review of the recent literature describing applications of biophotonics in veterinary medicine. Here, we focus only on the studies with a clear goal to solve a veterinary challenge. Therefore, if animals were used as models or if the animalistic purpose was not clear, the paper was not taken into account. Further, we explored the opportunities of biophotonics in small animal medicine. Finally, our recent work with a pulse oximeter for canine monitoring is briefly presented.

*blaz.cugmas@lu.lv; phone +371 67228249; http://www.asi.lv/

Optical Diagnostics and Sensing XIX: Toward Point-of-Care Diagnostics, edited by Gerard L. Coté, Proc. of SPIE Vol. 10885, 108850I - (C) 2019 SPIE · CCC code: 1605-7422/19/\$18 - doi: 10.1117/12.2507980 


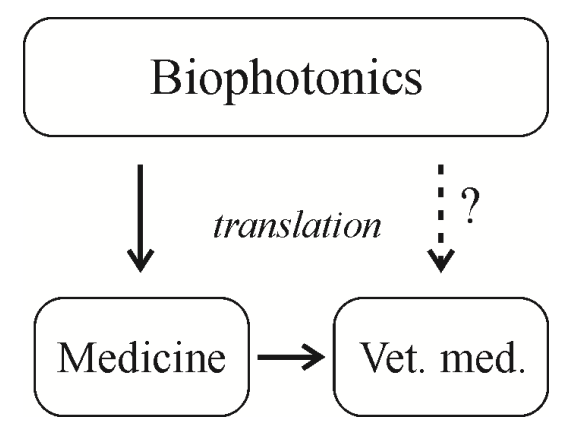

Figure 1. Biophotonics techniques are first translated to (human) medicine. There are rare cases when the optical device is designed especially for animals and translated directly to veterinary medicine.

\section{CHARACTERISTICS OF VETERINARY MEDICINE}

Veterinary medicine handles non-human aspects of medicine, including preventive, diagnostic and, therapeutic procedures. It also cooperates closely with medical institutions to control diseases, which can be dangerous to humans (i.e., zoonotic diseases) ${ }^{3}$. Zoonosis can be transmitted by air (e.g., influenza), contact (e.g., rabies), or with food (e.g., Salmonella or Campylobacter infection). Therefore, an important aspect of veterinary medicine is also monitoring animal-origin food quality and safety ${ }^{4}$. Besides meat, veterinarians inspect eggs, honey, seafood and, dairy products.

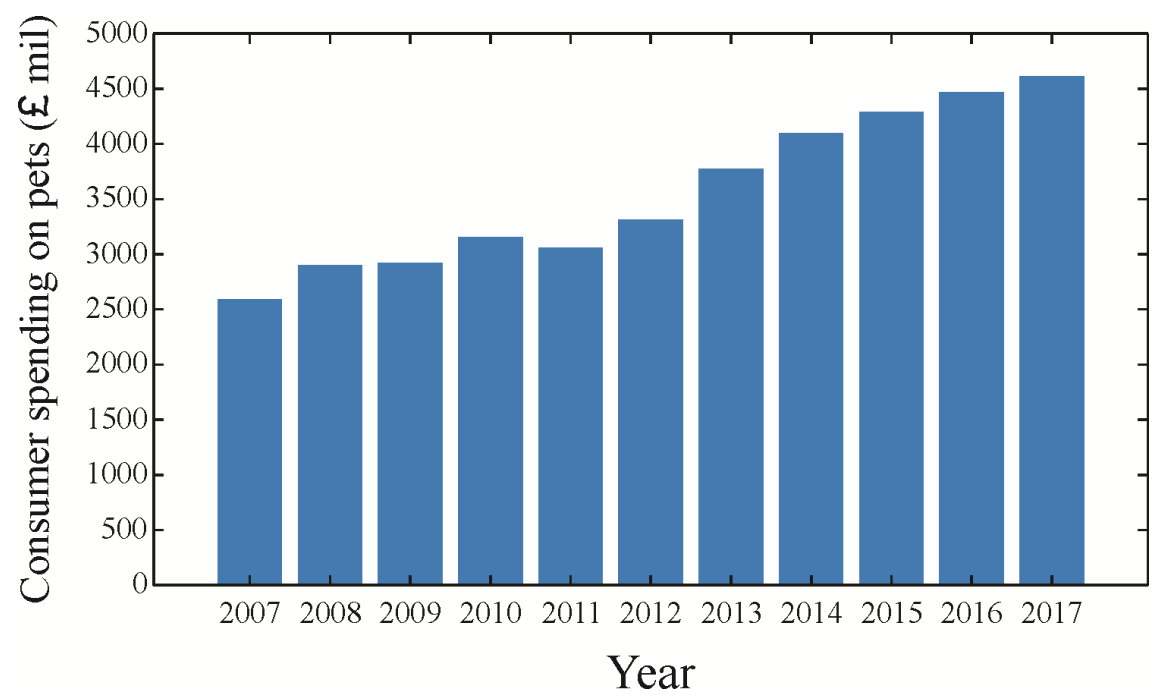

Figure 2. Consumer spending on pets in the UK between 2007 and $2017^{5}$.

More than 117,000 veterinarians worked in private and public veterinary institutions in the USA in $2017^{6}$. In Europe, there are around 243,000 veterinarians, responsible for 157 million companion animals and 342 million farm animals ${ }^{7}$. Yearly revenues per European veterinarian in 2015 were a bit more than $€ 110,000$ (ca. $\$ 125,000$ ). $72 \%$ of revenue is generated by companion animal-related services ${ }^{7}$. In the last ten years, consumer spending on pets and related products in the United Kingdom almost doubled (Figure 2$)^{5}$. However, the average veterinary practice is small as more than $80 \%$ of clinics employ less than ten people. In the US, the average veterinary practice has only 2.38 veterinarians ${ }^{8}$. Additionally, the revenues from pet food sales in Europe in 2017 were $€ 20.5$ billion with the average growth rate of $2 \%{ }^{\circ}$. Various food diets which correspond to different animal activity levels or medical conditions (e.g., diseases, allergies), are especially popular. 


\subsection{Companion animals}

In the European Union, the most common companion animals are dogs and cats ${ }^{7}$. However, other pets as horses, rabbits, rodents, birds and, reptiles often need medical help as well. The veterinary approach is similar to human since companion animals do not possess just monetary but also a psychological and social value to owners. That calls for personalized and state-of-the-art medicine what is reflected in many published professional guidelines from the veterinary organizations like American Animal Hospital Association (AAHA), American Veterinary Medical Association (AVMA), British Small Animal Association (BSAVA), which are expected to be followed by the practitioners. At the average veterinary clinic, despite small in size, a pet can receive a complete set of preventive (e.g., vaccination), diagnostic (e.g., physical examination, blood analysis, x-ray) and therapeutic services (e.g., sterilization, drug administration, surgery).

Modern veterinary clinics are equipped with state-of-the-art medical technologies such as digital x-ray, blood analyzer and, ultrasound. Almost every clinic possesses a microscope, which serves for the inspection of blood smears, plucked hair (i.e., trichogram), swabs and other tissues taken by the fine-needle procedure (also, biopsy). Additionally, Wood's lamp ${ }^{10}$ can help to diagnose dermatophytosis due to the autofluorescence of fungus Microsporum canis ${ }^{11}$. Some clinics have various therapeutic lasers, mostly applied for wound management. Electronic health record systems (EHR) are becoming the dominant way of tracking health documentation and providing business functionalities ${ }^{12}$. Moreover, telemedicine ${ }^{13}$, webpage and social media are important communication channels between caregivers and pet owners.

\subsection{Farmed animals}

Although medicine for companion animals is highly personalized, the same cannot be said for farmed animals (also farm animals, livestock). Farmed animals exhibit mainly monetary (also economic) value; therefore, the choice of veterinary services depends on the ratio between animal value and service cost. Since livestock such as chicken, rabbits and small ruminants have low monetary value, the veterinary approach is often preventive, and it focuses on the whole herd (e.g., antiparasitic treatments, vaccinations). Animals with higher monetary value (e.g., cattle) get basic medical services as infection therapy and simple surgery. Only very precious animals (e.g., animals with specific breeding potential) receive more sophisticated and expensive veterinary treatment. In general, reproduction management and feed conversion efficiency are the main interest since they impact the economics the most.

\section{CURRENT STATE-OF-THE-ART: A BRIEF REVIEW}

In this brief review, we focused on novel papers up to ten years old, describing biophotonics applications exclusively for veterinary medicine. We identified 43 papers which can be placed into four categories concerning oncology (tumors), measuring various physiological parameters, photobiomodulation, and thermography (Table 1).

Table 1. Recent studies on biophotonics in veterinary medicine.

\begin{tabular}{|c|c|}
\hline Category & Main focus \\
\hline Oncology & $\begin{array}{c}\text { diagnosis (skin and subcutaneous tumors), } \\
\text { prognosis (lymphoma), } \\
\text { therapy (clear surgical margins) }\end{array}$ \\
\hline Physiology & various circulation indices $\left(\mathrm{StO}_{2}, \mathrm{rSO}_{2}, \mathrm{HbI}, \mathrm{CRT}\right)^{*}$ \\
\hline Photobiomodulation & $\begin{array}{l}\text { therapy (wounds, skin conditions, orthopedics), } \\
\text { results are contradictory }\end{array}$ \\
\hline Thermography & $\begin{array}{l}\text { diagnosis (orthopedics, } \\
\text { diseases as infections and hyperthyroidism) }\end{array}$ \\
\hline
\end{tabular}




\subsection{Oncology}

Cancer is the main cause of companion animal morbidity and mortality ${ }^{14}$. As in humans, biophotonics can contribute to the cheaper, faster and, less painful oncological diagnosis, prognosis and, therapy.

Diagnosis

Diffuse reflectance spectroscopy (DRS) has been applied for in vivo and in vitro detection of canine malignant skin and subcutaneous tumors with the sensitivity up to $90 \%$. However, specificity was quite low, only between $54.6 \%$ and $73.5 \%{ }^{15}$. A higher specificity of $94.6 \%$ (sensitivity $85.7 \%$ ) was obtained with hyperspectral imaging which served for differentiation between malignant and benign mammary tumors in $22 \operatorname{dogs}^{16}$. Additionally, canine and feline sarcomas were studied by optical coherence tomography (OCT). Texture-based OCT image processing metrics were different for sarcomas, muscles and adipose tissue ${ }^{17,18}$. Undirectly, tumors can also be detected via certain blood markers. UV absorbance and photoluminescence spectra of serum albumin, globulins, and hemoglobin were acquired to distinguish between cancer and normal patients. $70 \%$ of all cancer patients were correctly identified ( $20 \%$ false positives $)^{19}$.

The histological examination of biopsy normally gives a final tumor diagnosis. Here, RGB imaging with fluorescence can help to visualize mast cell tumor (MCT) structures. Mast cell granules emitted a specific yellow color ${ }^{20}$.

Prognosis

Biodynamic imaging (BDI) was used ex vivo on 19 dogs with non-Hodgkin lymphoma (NHL) to predict their response to chemotherapy (CHOP therapy) ${ }^{21}$. The prediction accuracy was $84 \%$. The authors believe that results could personalize the chemotherapy and by that, avoid unnecessary interventions.

\section{Therapy}

Tumors are often removed by conventional surgery where it is important to achieve clear surgical margins. In practice, this is hard to deliver. RGB or near-infrared (NIR) fluorescence imaging can be beneficial to detect residual cancer cells in surgical margins. In one study, fluorescence LUM015 agent assisted the differentiation between sarcomas and mast cell tumors in 19 dogs. In $92 \%$ of cases, the system correctly detected cancerous or normal tissue ${ }^{22}$. In the second study, NIR fluorescence images matched histopathological interpretation of the diverse group of tumors (perivascular tumors, sarcomas) in $15 \mathrm{dogs}^{23}$. There are also many near-infrared fluorescent contrast agents which have potential in veterinary oncology $\mathrm{y}^{24}$.

\subsection{Physiological parameters}

Monitoring decreased tissue oxygen saturation $\left(\mathrm{StO}_{2}\right)$ is crucial in critically ill patients for maintaining the adequate oxygen delivery ${ }^{25}$. Noninvasive $\mathrm{StO} 2$ monitoring methods include near-infrared spectroscopy (NIRS), dark field videomicroscopy, or Doppler flowmetry. In dogs, we found only studies with NIRS applied. Apart from a pulse oximeter, NIRS based devices rely more on wavelengths between 700 and $1000 \mathrm{~nm}^{25,26}$. Sartorius muscle was a recommended measurement site due to ease of positioning, limited hair, and minimal skin pigment ${ }^{27}$. Expectedly, lower $\mathrm{StO}_{2}$ was measured in patients with various traumatic conditions as acute hemorrhagic shock and hypoxemia ${ }^{28-30}$.

Additionally, two different NIRS monitors were compared ${ }^{31}$. The comparison resulted in various and generally lower $\mathrm{StO}_{2}$ values of one monitor which point to unsteady measurements. The potential future work in veterinary medicine can be an evaluation of patients with trauma, sepsis, and surgical diseases, and to detect occult shock ${ }^{25}$. Additionally, cerebral and skeletal muscle oxygenation (regional saturation of oxygen $\left(\mathrm{rSO}_{2}\right)$ and total hemoglobin index $(\mathrm{HbI})$ ) was measured by finger-held NIRS device in small dogs (Chihuahua) $)^{32}$. Measuring oxy- and deoxy-hemoglobin with functional NIRS (fNIRS) can observe canine behavior changes ${ }^{33}$.

\subsection{Photobiomodulation therapy (PBMT)}

Despite the fact that photobiomodulation therapy (PBMT) is more than 50 years old, it is one of the most controversial biophotonics techniques ${ }^{34}$. The positive effects of low-level laser therapy (LLLT), the old name for PBMT, on cells and tissues have been shown in vitro or on the models (mostly rats), but the in vivo results are often conflicting and the PBMT therapeutic benefit questionable. Some studies claim that many negative trials appeared due to the variations in study designs ${ }^{35}$. 
PBMT has become an important part of veterinary medicine ${ }^{36-38}$. PBMT, as a therapeutic method, was studied on wounds, bone ${ }^{39}$ or cartilage, arthritis, ligament or tendon, analgesia, nociceptors, nerves, and spinal cord. So far, the most promising results appear in the management of cartilage and nerve injuries, and lick granulomas (also lick dermatitis) ${ }^{36}$.

Recent studies have expressed doubts about PBMT. First, laser therapy, initially described in 1968, showed potential for more effective wound management by normalizing cell function, stimulating collagen alignment and enhancing the local blood flow ${ }^{37}$. However, PBMT did not appear to influence the healing time of acute or surgically created wounds in $\operatorname{dogs}^{40,41}$. Similarly confusing are studies on postoperative recovery of dogs undergoing hemilaminectomy (i.e., surgical procedure after intervertebral disk herniation) and osteotomy. On the one hand, studies showed that PBMT reduces time to ambulation due to reducing pain, edema, and inflammation ${ }^{42}$ and increase gait functionality ${ }^{43}$. On the other hand, there was no difference in recoveries and pain of dogs, which received PBMT and sham therapy ${ }^{44,45}$.

In veterinary dermatology, PBMT was used for the treatment of various dermatitis (acral lick, pyotraumatic, folliculitis), anal sacculitis, hematoma, pemphigus, alopecia, and cellulitis ${ }^{37,46,47}$.

\subsection{Thermography}

Thermography is based on the infrared range between 9 and $14 \mu \mathrm{m}$. On the other hand, biophotonics includes techniques with the upper wavelength range of $10.6 \mu \mathrm{m}^{1}$. Therefore, thermography is more borderline than typical biophotonics technique. However, it seems that thermography is one of the most studied optical (imaging) method in veterinary medicine ${ }^{48}$; therefore, we decided to dedicate one section to this field as well.

In animals, thermography represents a potentially safer and cheaper alternative to $\mathrm{x}$-ray, $\mathrm{CT}$ and, $\mathrm{MRI}^{49,50}$. The technique was applied to study various viral or bacterial diseases, orthopedic conditions like laminitis, tissue perfusion, reproduction issues, production, and welfare ${ }^{48}$. In dogs, thermography was used for diagnosing bone cancer (sensitivity $100 \%$, specificity $80 \%)^{50}$. The rest of the problems addressed by thermography belonged to orthopedics where an anterior cruciate ligament $(\mathrm{ACL})^{49}$, hips, stifles, elbows, and disc disease were studied ${ }^{51,52}$. In cats, thermal imaging detected hyperthyroidism with $87.5 \%$ accuracy $^{53}$. Thermography is popular also in horses, where the technique was used to detect various diseases (e.g., Horner's syndrome, neurectomies) and to address various challenges in equine orthopedics $^{54,55}$.

\subsection{Other applications}

Fluorescence spectroscopy was used for analyzing urine from healthy dogs and dogs with various disorders (cancer, portosystemic shunt, fever, renal failure, and Cushing's disease). The authors discovered that the studied disorders impact urine fluorescent attributes ${ }^{56}$. Besides urine, blood samples were analyzed by Fourier transform infrared spectroscopy (FTIR) in order to distinguish between healthy dogs, dogs with nonfood-induced canine atopic dermatitis, and dogs with non-allergic inflammation ${ }^{57}$. Additionally, visible and NIR spectroscopy was used for detection of chondrodystrophoid canine intervertebral discs ${ }^{58}$.

\section{FUTURE CHALLENGES}

As showed in Section 3, biophotonics has just started its journey across the field of veterinary medicine and by that, many opportunities arise in every (veterinary) direction. One of the biggest issues in the field is patient behavior. With humans, relative physical and emotional serenity can be achieved for measurements. That certainly cannot be said for pets since they like moving, avoiding, jumping, barking, and scratching, not just due to fear, sometimes also due to positive excitement. Therefore, simple and short procedures as temperature measurement (rectally) or blood collection (from the cephalic vein on the front leg) can become very challenging. Also, devices and prototypes are in danger and are often in for repair.

Non-invasive techniques would be especially welcomed. For example, diagnosing superficial tumors (e.g., skin and subcutaneous tumors) requires fine-needle aspiration (FNA) procedure. Since benign tumors represent at least $38 \%$ of all tumors (a pet can often have multiple benign lesions) ${ }^{59}$, FNA is not very practical. Conventional spectroscopy (DRS) has already been tested for the tumor diagnostics ${ }^{15}$, but the more portable and user-friendly system would be convenient. If economically sound, handheld OCT, currently being introduced to human clinics ${ }^{60}$, could be a solution. What is more, fluorescence could accelerate and facilitate classical tumors diagnostics (i.e., histopathology), in vivo ${ }^{61}$ or when biopsy has already been performed. Finally, optical techniques can detect tumor biomarkers ${ }^{62,63}$ or tumorous cells directly ${ }^{64}$. 
Table 2. Identified main challenges of biophotonics in veterinary medicine.

\begin{tabular}{l|c}
\hline Category & Challenge \\
\hline Device design & $\begin{array}{l}\text { Robust optical devices which will offer } \\
\text { simple and short measuring procedures } \\
\text { Cncology }\end{array}$ \\
Pulse oximeter & $\begin{array}{c}\text { Can biophotonics replace FNA?* } \\
\text { further sensor exploitation for } \\
\text { pet mitoring }\end{array}$ \\
Photobiomodulation & $\begin{array}{l}\text { extensive clinical (in vivo) study needed, } \\
\text { less painful approach in dental medicine }\end{array}$ \\
\hline *FNA (fine-needle aspiration procedure)
\end{tabular}

As discussed in the next section, pulse oximeter has big potential in pet monitoring ${ }^{65}$. We think that new probes adjusted to animal anatomy and physiology should be developed and clinically tested. That will allow performing more specific PPG studies on pulse transit times (PTT), PPG pulse shape, etc. For example, the acquired data could serve for optical blood pressure estimation ${ }^{66}$.

PBMT is highly promoted in veterinary medicine, but good clinical (in vivo) studies are missing ${ }^{67}$. In major books, only separate clinical cases are presented. However, it seems that lasers can be applied less painfully, e.g., when performing surgery of maxillary and mandibular bone ${ }^{39}$. Another beneficial PBMT contribution would be in veterinary dentistry since most of the dental procedures require (expensive) anesthesia. Treating periodontal disease could be especially welcomed.

\section{RECENT RESULTS}

Recently, we have been exploiting the monitoring potential of a pulse oximeter in small animal medicine. First, we studied photoplethysmography (PPG) signal quality on several canine and feline measurement sites that would be better tolerated than the oral sensor placement by conscious animals ${ }^{65}$. We discovered that a pet monitor with pulse oximeter could be applied on the canine metacarpus or the tail. In cats, the digit could be used. Secondly, an optical device was tested on various measurement sites for the estimation of canine capillary refill time $(\mathrm{CRT})^{68,69}$. CRT is a part of the cardiorespiratory examination and can reflect pathological conditions like shock or anemia. In both studies, we identified the metacarpal pad, digit, or tail as a potential site for CRT estimation by the proposed device. However, many measurements were affected by heavy pigmentation, motion artifacts, and other contact-pressure related effects ${ }^{70}$.

Currently, we are testing if the pulse oximeter can improve CADESI-4 scale ${ }^{71}$ for canine atopic dermatitis severity by introducing objective erythema index (EI) estimation. Since our pulse oximeter included green and red LEDs, two EI equations were employed ${ }^{72}$ :

$$
\begin{gathered}
E I_{1}=R / G, \\
E I_{2}=(G-R) /(G+R),
\end{gathered}
$$

where $G$ and $R$ are green and red optical signals, respectively. We applied linear regression between clinician estimatederythema level (EL, $0-3$ or $0-100 \%$ ) as an independent variable and measured $\mathrm{EI}_{1}$ or $\mathrm{EI}_{2}$. The results with eight dogs (inguinal measurement site) are presented in Table 3 and Figure 2. R-squared was between 0.54 and 0.71 what points to the potential of a pulse oximeter to benefit CADESI-4 scale.

Table 3. R-squared $\left(\mathrm{r}^{2}\right)$ of linear regression analysis. 


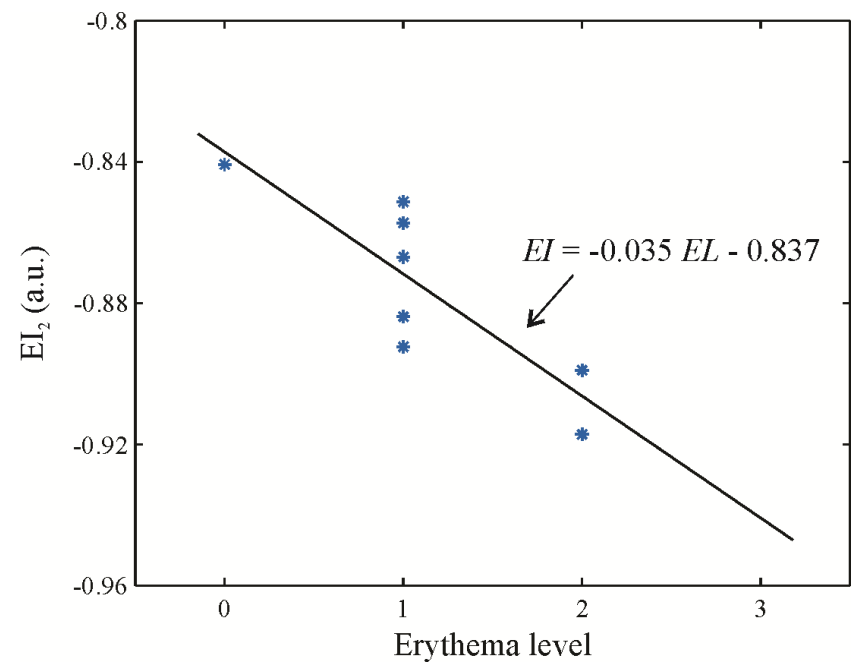

Figure 3. Linear regression fitted line between erythema level (EL) and erythema index (EI).

\section{CONCLUSION}

Biophotonics and biomedical optics are predominantly applied in human medicine. However, veterinary science is developing rapidly as well, because pets are becoming more and more emotionally valuable. We believe that biophotonics should be translated directly into veterinary practice accordingly to peculiar animal needs (different anatomy and behavior). We think that various optical methods can contribute to veterinary oncology (e.g., spectral imaging), monitoring (e.g., pulse oximeter), and dentistry (e.g., photobiomodulation).

\section{ACKNOWLEDGMENTS}

The study was supported by the Marie Skłodowska-Curie actions of the European Union (IF, DogSPEC, 745396). We would also like to express our gratitude to Liene Dindone and Alla Olivrī (Animal Health Centre, Riga, Latvia), Inga Saknīte (Vanderbilt University Medical Center, Nashville, USA), and Tanja Knific (University of Ljubljana, Ljubljana, Slovenia) for all the help with preparing this paper.

\section{REFERENCES}

[1] Keiser, G., [Biophotonics: Concepts to Applications], Springer Singapore, Singapore (2016).

[2] Olivo, M. and Dinish, U. S., eds., [Frontiers in Biophotonics for Translational Medicine], Springer Singapore, Singapore (2016).

[3] Kahn, L. H., "Confronting zoonoses, linking human and veterinary medicine,” Emerg. Infect. Dis. 12(4), 556-561 (2006).

[4] Wilson, W., [Wilson's Practical Meat Inspection], Wiley-Blackwell, Oxford (2005).

[5] Statista, "Consumer spending on pets and related products in the United Kingdom (UK) from 2005 to 2017.", Hamburg, 2018, <https://www.statista.com/statistics/308266/consumer-spending-on-pets-and-related-products-inthe-united-kingdom-uk/> (22 November 2018).

[6] AVMA, "Market Research Statistics: U.S. Veterinarians 2017," Schaumburg, 2017, $<$ https://www.avma.org/KB/Resources/Statistics/Pages/Market-research-statistics-US-veterinarians.aspx > (1 January 2019). 
[7] FVE Survey of the Veterinary Profession in Europe 2015., Mirza \& Nacey Research, Ford Arundel, United Kingdom (2015).

[8] Dicks, M. R., "Economics of the Veterinary Profession: Connecting the Dots,", VHMA 2017 Annual Meeting and Conference, 2017, New Orleans.

[9] Fediaf, "European Facts \& Figures 2017”, Bruxelles, 2017, < http://www.fediaf.org/component/attachments/attachments.html?task=attachment\&id=2019> (1 January 2019).

[10] Asawanonda, P. and Taylor, C. R., "Wood's light in dermatology,” Int. J. Dermatol. 38(11), 801-807 (2001).

[11] Moriello, K. A., Coyner, K., Paterson, S. and Mignon, B., "Diagnosis and treatment of dermatophytosis in dogs and cats.," Vet. Dermatol. 28(3), 266-e68 (2017).

[12] Krone, L. M., Brown, C. M. and Lindenmayer, J. M., "Survey of electronic veterinary medical record adoption and use by independent small animal veterinary medical practices in Massachusetts," J. Am. Vet. Med. Assoc. 245(3), 324-332 (2014).

[13] Bishop, G. T., Evans, B. A., Kyle, K. L. and Kogan, L. R., "Owner satisfaction with use of videoconferencing for recheck examinations following routine surgical sterilization in dogs," J. Am. Vet. Med. Assoc. 253(9), 11511157 (2018).

[14] Withrow, S., Vail, D. and Page, R., "Why Worry About Cancer in Companion Animals?," [Withrow \& MacEwen's Small Animal Clinical Oncology (Fifth Edition)], S. Withrow, D. Vail, and R. Page, Eds., W.B. Saunders, Saint Louis, xv-xvi (2013).

[15] Cugmas, B., Plavec, T., Bregar, M., Naglič, P., Pernuš, F., Likar, B. and Bürmen, M., "Detection of canine skin and subcutaneous tumors by visible and near-infrared diffuse reflectance spectroscopy,” J. Biomed. Opt. 20(3), 037003 (2015).

[16] Sahu, A., McGoverin, C., Pleshko, N., Sorenmo, K. and Won, C.-H., "Hyperspectral imaging system to discern malignant and benign canine mammary tumors," Proc. SPIE 8719 (2013).

[17] Mesa, K. J., Selmic, L. E., Pande, P., Monroy, G. L., Reagan, J., Samuelson, J., Driskell, E., Li, J., Marjanovic, M., Chaney, E. J. and Boppart, S. A., "Intraoperative optical coherence tomography for soft tissue sarcoma differentiation and margin identification," Lasers Surg. Med. 49(3), 240-248 (2017).

[18] Selmic, L. E., Samuelson, J., Reagan, J. K., Mesa, K. J., Driskell, E., Li, J., Marjanovic, M. and Boppart, S. A., "Intra-operative imaging of surgical margins of canine soft tissue sarcoma using optical coherence tomography," Vet. Comp. Oncol. (2018). Doi: 10.1111/vco.12448.

[19] Dickerson, B., Geist, B. L., Spillman, W. B. and Robertson, J. L., "Canine cancer screening via ultraviolet absorbance and fluorescence spectroscopy of serum proteins," Appl. Opt. 46(33), 8080-8088 (2007).

[20] Fereidouni, F., Griffin, C., Todd, A. and Levenson, R., "Multispectral analysis tools can increase utility of RGB color images in histology," J. Opt. 20(4), 044007 (2018).

[21] Choi, H., Li, Z., Sun, H., Merrill, D., Turek, J., Childress, M. and Nolte, D., "Biodynamic digital holography of chemoresistance in a pre-clinical trial of canine B-cell lymphoma," Biomed. Opt. Express 9(5), 2214-2228 (2018).

[22] Bartholf DeWitt, S., Eward, W. C., Eward, C. A., Lazarides, A. L., Whitley, M. J., Ferrer, J. M., Brigman, B. E., Kirsch, D. G. and Berg, J., "A Novel Imaging System Distinguishes Neoplastic from Normal Tissue During Resection of Soft Tissue Sarcomas and Mast Cell Tumors in Dogs,” Vet. Surg. 45(6), 715-722 (2016).

[23] Holt, D., Parthasarathy, A. B., Okusanya, O. T., Keating, J., Venegas, O., Deshpande, C., Karakousis, G. C., Madajewski, B., Durham, A., Nie, S., Yodh, A. G. and Singhal, S., "Intraoperative near-infrared fluorescence imaging and spectroscopy identifies residual tumor cells in wounds," J Biomed Opt. 20(7), 076002 (2015).

[24] Favril, S., Abma, E., Blasi, F., Stock, E., Devriendt, N., Vanderperren, K. and de Rooster, H., "Clinical use of organic near-infrared fluorescent contrast agents in image-guided oncologic procedures and its potential in veterinary oncology,” Vet. Rec. 183(11), 354 (2018).

[25] Salcedo, M. C., Tart, K. and Hall, K., "A systematic review of human and veterinary applications of noninvasive tissue oxygen monitoring,” J. Vet. Emerg. Crit. Care 26(3), 323-332 (2016).

[26] Epstein, C. D. and Haghenbeck, K. T., "Bedside assessment of tissue oxygen saturation monitoring in critically ill adults: an integrative review of the literature," Crit. Care Res. Pract. 2014, 709683 (2014).

[27] Hall, K. E., Powell, L. L., Beilman, G. J., Shafer, K. R., Skala, V. K. and Olmstead, E. A., "Measurement of tissue oxygen saturation levels using portable near-infrared spectroscopy in clinically healthy dogs," J. Vet. Emerg. Crit. Care 18(6), 594-600 (2008).

[28] Pavlisko, N. D., Henao-Guerrero, N., Killos, M. B., Ricco, C., Shih, A. C., Bandt, C. and Werre, S. R., "Evaluation of tissue oxygen saturation with near-infrared spectroscopy during experimental acute hemorrhagic shock and resuscitation in dogs," Am. J. Vet. Res. 75(1), 48-53 (2013). 
[29] Pavlisko, N. D., Killos, M., Henao-Guerrero, N., Riccó, C. H. and Werre, S., "Evaluation of tissue hemoglobin saturation (StO2) using near-infrared spectroscopy during hypoxemia and hyperoxemia in Beagle dogs," Vet. Anaesth. Analg. 43(1), 18-26 (2016).

[30] Gray, S. L., Hall, K. E., Powell, L. L., Schildt, J., Brearley, A. M. and Beilman, G. J., "Tissue oxygen saturation in dogs with acute hemorrhage," J. Vet. Emerg. Crit. Care 28(5), 408-414 (2018).

[31] Engbers, S., Boysen, S. R., Engbers, J. and Chalhoub, S., "A comparison of tissue oxygen saturation measurements by 2 different near-infrared spectroscopy monitors in 21 healthy dogs," J. Vet. Emerg. Crit. Care 24(5), 536-544 (2014).

[32] Hiwatashi, K., Doi, K., Mizuno, R. and Yokosuka, M., "Examiner's finger-mounted near-infrared spectroscopy is feasible to analyze cerebral and skeletal muscle oxygenation in conscious Chihuahuas," J. Biomed. Opt. 22(2), 026006-22-26 (2017).

[33] Gygax, L., Reefmann, N., Pilheden, T., Scholkmann, F. and Keeling, L., "Dog behavior but not frontal brain reaction changes in repeated positive interactions with a human: A non-invasive pilot study using functional nearinfrared spectroscopy (fNIRS)," Behav. Brain Res. 281, 172-176 (2015).

[34] Hamblin, M. R., "Photobiomodulation or low-level laser therapy," J. Biophotonics 9(11-12), 1122-1124 (2016).

[35] Tuner, J. and Hode, L., "It's All in the Parameters: A Critical Analysis of Some Well-Known Negative Studies on Low-Level Laser Therapy,” J. Clin. Laser Med. Surg. 16(5), 245-248 (1998).

[36] Millis, D. L. and Gross Saunders, D., "Laser Therapy in Canine Rehabilitation," [Canine Rehabilitation and Physical Therapy], D. Millis and D. Levine, Eds., Saunders, Philadelphia, 359-380 (2013).

[37] Riegel, R. J. and Godbold Jr., J. C., [Laser Therapy in Veterinary Medicine: Photobiomodulation, 1st Edition], John Wiley \& Sons, Inc. (2017).

[38] Hochman, L., "Photobiomodulation Therapy in Veterinary Medicine: A Review," Top. Companion Anim. Med. 33(3), 83-88 (2018).

[39] Mrotek, M., "Modeling of light propagation in canine gingiva," Proc. SPIE 10455 (2017).

[40] Kurach, L. M., Stanley, B. J., Gazzola, K. M., Fritz, M. C., Steficek, B. A., Hauptman, J. G. and Seymour, K. J., "The Effect of Low-Level Laser Therapy on the Healing of Open Wounds in Dogs," Vet. Surg. 44(8), 988-996 (2015).

[41] Gammel, J. E., Biskup, J. J., Drum, M. G., Newkirk, K. and Lux, C. N., "Effects of low-level laser therapy on the healing of surgically closed incisions and surgically created open wounds in dogs," Vet. Surg. 47(4), 499-506 (2018).

[42] Draper, W. E., Schubert, T. A., Clemmons, R. M. and Miles, S. A., "Low-level laser therapy reduces time to ambulation in dogs after hemilaminectomy: a preliminary study," J. Small Anim. Pract. 53(8), 465-469 (2012).

[43] Rogatko, C. P., Baltzer, W. I. and Tennant, R., "Preoperative low level laser therapy in dogs undergoing tibial plateau levelling osteotomy: A blinded, prospective, randomized clinical trial," Vet. Comp. Orthop. Traumatol. 30(01), 46-53 (2017).

[44] Bennaim, M., Porato, M., Jarleton, A., Hamon, M., Carroll, J. D., Gommeren, K. and Balligand, M., "Preliminary evaluation of the effects of photobiomodulation therapy and physical rehabilitation on early postoperative recovery of dogs undergoing hemilaminectomy for treatment of thoracolumbar intervertebral disk disease," Am. J. Vet. Res. 78(2), 195-206 (2017).

[45] Kennedy, K. C., Martinez, S. A., Martinez, S. E., Tucker, R. L. and Davies, N. M., "Effects of low-level laser therapy on bone healing and signs of pain in dogs following tibial plateau leveling osteotomy," Am. J. Vet. Res. 79(8), 893-904 (2018).

[46] Olivieri, L., Cavina, D., Radicchi, G., Miragliotta, V. and Abramo, F., "Efficacy of low-level laser therapy on hair regrowth in dogs with noninflammatory alopecia: a pilot study," Vet. Dermatol. 26(1), 35-e11 (2014).

[47] Perego, R., Proverbio, D., Zuccaro, A. and Spada, E., "Low-level laser therapy: Case-control study in dogs with sterile pyogranulomatous pododermatitis," Vet. World 9(8), 882-887 (2016).

[48] Rekant, S. I., Lyons, M. A., Pacheco, J. M., Arzt, J. and Rodriguez, L. L., "Veterinary applications of infrared thermography," Am. J. Vet. Res. 77(1), 98-107 (2015).

[49] Lama, N., Umbaugh, S. E., Mishra, D., Dahal, R., Marino, D. J. and Sackman, J., "Thermography based diagnosis of ruptured anterior cruciate ligament (ACL) in canines," Proc. SPIE. 9971 (2016).

[50] Subedi, S., Umbaugh, S. E., Fu, J., Marino, D. J., Loughin, C. A. and Sackman, J., "Thermographic image analysis as a pre-screening tool for the detection of canine bone cancer," Proc. SPIE 9217 (2014).

[51] Brown, J. and Henneman, K. E., "Imaging in Canine Sports Medicine," [Canine Sports Medicine and Rehabilitation], John Wiley \& Sons, Ltd, 502-519 (2018). 
[52] Garcia, E. F. V., Loughin, C. A., Marino, D. J., Sackman, J., Umbaugh, S. E., Fu, J., Subedi, S., Lesser, M. L., Akerman, M. and Schossler, J. E. W., "Medical infrared imaging and orthostatic analysis to determine lameness in the pelvic limbs of dogs," Open Vet. J. 7(4), 342-348 (2017).

[53] Waddell, R. E., Marino, D. J., Loughin, C. A., Tumulty, J. W., Dewey, C. W. and Sackman, J., "Medical infrared thermal imaging of cats with hyperthyroidism," Am. J. Vet. Res. 76(1), 53-59 (2014).

[54] Soroko, M., Henklewski, R., Filipowski, H. and Jodkowska, E., "The Effectiveness of Thermographic Analysis in Equine Orthopedics," J. Equine Vet. Sci. 33(9), 760-762 (2013).

[55] Redaelli, V., Bergero, D., Zucca, E., Ferrucci, F., Costa, L. N., Crosta, L. and Luzi, F., "Use of Thermography Techniques in Equines: Principles and Applications," J. Equine Vet. Sci. 34(3), 345-350 (2014).

[56] Šteffeková, Z., Birková, A., Baranová, D. and Mareková, M., "Pilot Study of Canine Urine Analysis Using Fluorescent Fingerprint," Spectrosc. Lett. 48(6), 447-453 (2015).

[57] Bruet, V., Dumon, H., Bourdeau, P., Desfontis, J.-C. and Martin, L., "Prospective pilot study to detect dogs with non food-induced canine atopic dermatitis using Fourier transform infrared spectroscopy," Vet. Dermatol. 27(5), 356-e89 (2016).

[58] Jiang, Y., McKeirnan, K., Piao, D. and Bartels, K. E., "Feasibility of minimally-invasive fiber-based evaluation of chondrodystrophoid canine intervertebral discs by light absorption and scattering spectroscopy," Proc. SPIE. 7895 (2011).

[59] Hauck, L., "Tumors of the Skin and Subcutaneous Tissues," [Withrow \& MacEwen's Small Animal Clinical Oncology (Fifth Edition)], S. Withrow, D. Vail, and R. Page, Eds., W.B. Saunders, Saint Louis, 375-401 (2013).

[60] Monroy, G. L., Won, J., Spillman, D. R., Dsouza, R. and Boppart, S. A., "Clinical translation of handheld optical coherence tomography: practical considerations and recent advancements," J. Biomed. Opt. 22(12), 121715 (2017).

[61] Behrooz, A., Waterman, P., Vasquez, K. O., Meganck, J., Peterson, J. D., Faqir, I. and Kempner, J., "Multispectral open-air intraoperative fluorescence imaging," Opt. Lett. 42(15), 2964-2967 (2017).

[62] Henry, C. J., "Biomarkers in veterinary cancer screening: Applications, limitations and expectations," Spec. Issue Biomark. Vet. Med. 185(1), 10-14 (2010).

[63] Kaszak, I., Ruszczak, A., Kanafa, S., Kacprzak, K., Król, M. and Jurka, P., "Current biomarkers of canine mammary tumors," Acta Vet. Scand. 60(1), 66 (2018).

[64] Chmielewska, M., Łosiewicz, K., Socha, P., Męcik-Kronenberg, T. and Wąsowicz, K., "The application of circulating tumor cells detecting methods in veterinary oncology,” Pol. J. Vet. Sci. 16(1), 141-151 (2013).

[65] Cugmas, B., Štruc, E. and Spigulis, J., "Photoplethysmography in dogs and cats: a selection of alternative measurement sites for pet monitor," Physiol. Meas. (2018). Doi: 10.1088/1361-6579/aaf433.

[66] Xing, X. and Sun, M., "Optical blood pressure estimation with photoplethysmography and FFT-based neural networks," Biomed. Opt. Express 7(8) (2016).

[67] Paterniani, V. and Grolli, S., "Approach and potentiality of low level laser therapy in veterinary medicine," Proc. SPIE. 10582 (2018).

[68] Cugmas, B. and Spigulis, J., "Challenges in automated estimation of capillary refill time in dogs," Proc. SPIE. 10501 (2018).

[69] Cugmas, B., Štruc, E. and Spigulis, J., "Clinical evaluation of automated capillary refill time estimation in dogs and cats," Proc. SPIE. 10868 (2019).

[70] Cugmas, B., Bregar, M., Bürmen, M., Pernuš, F. and Likar, B., "Impact of contact pressure-induced spectral changes on soft-tissue classification in diffuse reflectance spectroscopy: problems and solutions," J. Biomed. Opt. 19(3), 037002 (2014).

[71] Olivry, T., Saridomichelakis, M., Nuttall, T., Bensignor, E., Griffin, C. E., Hill, P. B. and the International Committee on Allergic Diseases of Animals (ICADA)., "Validation of the Canine Atopic Dermatitis Extent and Severity Index (CADESI)-4, a simplified severity scale for assessing skin lesions of atopic dermatitis in dogs," Vet. Dermatol. 25(2), 77-85 (2014).

[72] Saknite, I., Zavorins, A., Jakovels, D., Spigulis, J. and Kisis, J., "Comparison of single-spot technique and RGB imaging for erythema index estimation," Physiol. Meas. 37(3), 333 (2016). 